\title{
Association between temperature and life table development of Fall armyworm Spodoptera frugiperda under control condition
}

\section{ADNT Thissa Kumara ( $\sim$ adntkumara@seu.ac.lk)}

South Eastern University of Sri Lanka https:// orcid.org/0000-0002-4670-2919

\section{Muhandiram AMKG}

South Eastern University of Sri Lanka

\section{Ranaweera GKMMK}

South Eastern University of Sri Lanka

Ayeshmanthi MB

South Eastern University of Sri Lanka

\section{SR Sarathchandra}

Rice Research Institute

\section{Mubarak ANM}

South Eastern University of Sri Lanka

\section{Research Article}

Keywords: Age specific fecundity, Cohort life tables, fall armyworm, longevity, temperature effects, Spodoptera frugiperda

Posted Date: January 26th, 2022

DOI: https://doi.org/10.21203/rs.3.rs-1295288/v1

License: (9) This work is licensed under a Creative Commons Attribution 4.0 International License. Read Full License 


\section{Abstract}

Fall armyworm Spodoptera frugiperda Smith (Lepidoptera: Noctuidae) (FAW) is one of the devastating polyphagous pests having a wide range of host plants that contribute substantial losses to crop cultivation. For such pests, temperatures exert a significant impact on biology, distribution, and abundance. Hence the present study was executed with the aims of evaluating the effects of different temperatures on the growth and development of fall armyworm. FAW larvae collected from the infested field and were reared in three different temperatures regimes viz. $25 \pm 1^{\circ} \mathrm{C}(\mathrm{T} 25), 30 \pm 1^{\circ} \mathrm{C}$ (T30) and 35 $\pm 1^{\circ} \mathrm{C}$ (T35) incubator provided with $12: 12$ photo period. Life table and fecundity tables were calculated using growth parameters. The results indicated that the mean duration of each stage of lifecycle at three different temperatures were significantly different from each other. The accumulated mortality at the adult stage was $95 \%, 61 \%$ and $64 \%$ at T35, T30 and T25 respectively. The net reproductive rate (Ro) was 132.17, the average period of generation time (Tc) was less in T30 (32.31) with the daily finite rate of increase in number $(\lambda)$ was 1.1702 females/female/day and a population doubling time of 3.004 days. Similarly, the intrinsic rate of natural increase in number (rm) was $0.1511 \mathrm{females} / \mathrm{female} / \mathrm{day}$ and hypothetical female population in the F2 generation was found to be higher at T30 (17468.20) thus the results indicated that T30 favors the growth and development of FAW compared to the other tested temperatures. Our findings could be useful for the implication in pest management and forecasting.

\section{Introduction}

The environmental, economic, and social impacts of invasive alien species are jeopardizing the livelihoods and food security of small-scale farmers in developing countries. (Early et al., 2016; Paini et al., 2016; Pratt et al., 2017). Among them, the Spodoptera frugiperda, also known as the fall armyworm (FAW), is a polyphagous lepidopteran pest native to tropical and subtropical America and mainly associated with maize crops (Cruz et al., 1999; Sarmento et al., 2002). It is a member of the genus Spodoptera, of the Noctuidae family, which is responsible for the world's highest monetary losses to agriculture (Groote et al., 2020) due to the nature of highly mobile insect pests infesting with a wide range of host crops. However, this tropical pest cannot survive in cold temperatures for long periods (Westbrook et al., 2015). Hence high variations in the weather in the Americas allow the FAW, to migrate to other countries, continually which has no diapause (Geogern et al., 2016). In late 2016, the first case of FAW was reported in West Africa and since spread rapidly across Sub-Saharan Africa, with its presence now confirmed in 44 African countries (Sisay et al., 2019). In 2018 it was reported in Asia damage was primarily in India (Karnataka) (Sharanabasappa et al., 2018). In Sri Lanka, a recent outbreak of FAW caused significant yield losses of maize, especially in the Uva, Eastern, and North Central provinces. The damage was first recorded in October 2018, and the majority of small-scale farming families have been severely (Perera et al., 2019). It was later recorded in the districts of Anuradhapura, Monaragala, Kurunegala, Kandy, Badulla and Rathnapura which belongs to Dry and dry intermediate agro ecological zones in the country (Wijerathna et al., 2020). As such the temperature might have a direct impact on the life cycle of FAW. 
Theoretically, the thermal optimum is define as the temperature at which a species thrives well in terms of growth, reproduction, and survival (Begon et al., 2006). When the maximum and minimum temperatures are within the species' optimum it promotes, insects' growth and development (Hagstrum \& Hagstrum, 1970: Howe, 1967). Further the length and number of each instar that larvae go through before reaching adulthood is influenced by temperature (Aguilon et al., 2015). Moreover, the relationship between temperature and development rate has a huge impact on pest biology, distribution, and abundance (Tobin et al., 2003). Increased ambient temperature near the thermal optimum of insects causes an increase in metabolic activities (Jaworski et al., 2013).

In ecological perspective, life tables are useful resources for evaluating, predicting and comprehending insect population development rates (Ashok et al., 2020). However, recent publications have focus on revealing the impact of FAW in selected specific temperatures, though the impact of various temperature has not been revealed. Owing to such limitations, our present study was carried out with the aim of evaluating the life tables of FAW on selected three different temperatures regimes under laboratory conditions.

\section{Materials And Methods}

\section{Insect stock colony}

The FAW larvae ( $F_{0}$ generation) were collected from naturally infected maize fields from the University experimental station at the Agrotech park Malwatte, the South Eastern University of Sri Lanka in Ampara district belongs to the low country dry zone (DL 2b; N 07 $19^{\prime} 17.30^{\prime \prime} \mathrm{E} 81^{\circ} 43^{\prime} 56.19$ ). The collected larvae were reared under constant laboratory conditions (Temperature $26 \pm 1{ }^{\circ} \mathrm{C}, 70 \% \mathrm{RH}$ and $12 \mathrm{~L}: 12 \mathrm{D}$ photoperiod) by providing a natural diet (Plessis et al., 2020) and maintained until the pupal stage in the Biosystems Technology laboratory facilities at the Faculty of Technology. The pupae were separated under the optical stereo microscope (LAB 20, Optika, Italy) according to the method previously described by Plessis et al., (2020). Separated pupae were placed in oviposition cages $(30 \mathrm{~cm} \mathrm{H}$. $\times 10 \mathrm{~cm} \mathrm{D}$.) for adult emergence.

\section{Life table study}

The uniform three batches of 100 to 150 eggs ( $F_{1}$ generation) were obtained from the stock $\left(F_{0}\right)$ colony and kept in three insect incubators (DI 120 Drag Lab Germany) and were maintained constant different temperature conditions viz. $25 \pm 1^{\circ} \mathrm{C}$ (T25), $30 \pm 1^{\circ} \mathrm{C}$ (T30) and $35 \pm 1^{\circ} \mathrm{C}$ (T35) until completion of progeny. The eggs were inspected under the Optical stereo microscope on daily basics to record the egg hatchability and days taken for hatching. As soon as $1^{\text {st }}$ instar larvae emerged, they were transferred to the individual transparent plastic bottles $(10 \mathrm{~cm} \mathrm{D.} \times 5 \mathrm{~cm} \mathrm{H}$.) and reared on the natural diet according to the Plessis et al., (2020). Then the individual larvae were observed under the optical stereo microscope to determine the duration of $1^{\text {st }}, 2^{\text {nd }}, 3^{\text {rd }}, 4^{\text {th }}, 5^{\text {th }}$ and $6^{\text {th }}$ larval instars and were recorded until pupation by 
observing at their head capsules and exuviae (Plessis et al., 2020). Moreover, the duration of prepupal, pupal and adult stages were recorded.

\section{Determination of oviposition, fecundity and longevity of FAW}

Ten couples from the emerging population of the above progeny were placed in oviposition cages and maintained in respective three different temperatures to obtain the age-specific fecundity data. The procedure continued until end of the adult emergence. A moistened muslin cloth was provided as oviposition substrate with $10 \%$ sucrose solution was provided to feed the adults. In each cage, the pre oviposition, oviposition, and post oviposition periods, number of eggs per day were recorded at daily intervals until the death of the female while oviposition substrate was replaced on a daily. Then the number of female birth $(\mathrm{mx})$ was estimated by assuming the 1:1 sex ratio as the number of eggs/day divided by two (Ashok et al., 2020).

\section{Determination of the age-specific fecundity tables}

The age-specific fecundity tables for different temperatures were prepared using daily observations of confined FAW couples (Equation 1, 2, 3 and 4 ) here $x=$ Pivotal age in days; $I x=$ Survival of female at age ' $X$ '; $m x=$ Age schedule for female births at age ' $X$ ' and $e=2.71828$. The Net productive rate (Ro) in generation as measured in females deliver per generation, Mean duration of generation (Tc) or mean age of the mothers in a cohort at the birth of female offspring, Innate capacity for increase $(\mathrm{rm})$ or at each age interval, the total number of individuals who survived and the mean number of female offspring births were recorded (Atwal \& Bains, 1974; Howe, 1953). Subsequently, estimated the precise generation time $(T)$, the finite rate of natural increase $(\lambda)$ or a number of females per female per day, the population's weekly multiplication and hypothetical $F_{2}$ females were calculated.

Net Reproductive rate $(\mathrm{Ro})=\sum l x m x$

Mean duration of generation $(\mathrm{Tc})=\frac{\sum l x m x}{R 0}$

Innate capacity for increase $(\mathrm{rm})=\frac{\log e R 0}{T c}$

Finite rate of natural increase $(\lambda)=$ antilog $\mathrm{e}^{\mathrm{rm}}$

\section{Cohort life tables}

Age-specific life table or cohort life table for fall armyworm was developed by Kyi et al., (1991) and Krebs (1978a and 2001b) Equation 5, 6, 7, 8 and 9 were used. The Krebs formulas were applied to calculate the results, $i$. e. $x=$ age interval (days) of each stage, egg, $1^{\text {st }}, 2^{\text {nd }}, 3^{\text {rd }}, 4^{\text {th }}, 5^{\text {th }}, 6^{\text {th }}$ larval instar, pupa and adult, 
$\mathrm{nx}=$ number of survivors at start of the age of interval $\mathrm{x}, \mathrm{dx}=$ number of dying during the age interval $\mathrm{x}$ to $x+1, q x$ is the rate of mortality during the age interval $x$ to $x+1, \mid x$ is the proportion of organisms surviving to start at age interval $x, L x$ is the number of individuals alive on the average during the age interval $x$ to $x+1$, Cumulative number of alive in age interval $x$ to $x+1, e_{x}$ mean expectation of life for organism alive at the start of age $x$.

Rate of mortality during the age interval $\mathrm{x}$ to $\mathrm{x}+1, \mathrm{qx}=\frac{d x}{n x}$
Proportion of organisms surviving to start at age interval $\mathrm{x}, \mathrm{lx}=\frac{n x}{n 0}$

Number of individuals alive on the average during the age interval $\mathrm{x}$ to $\mathrm{x}+1$,

$$
L x=\frac{n x+n x+1}{2}
$$

Cumulative number of alive in age interval $\mathrm{x}$ to $\mathrm{x}+1, T x=\sum_{x}^{\infty} \mathrm{Lx}$

Mean expectation of life for organism alive at the start of age $\mathrm{x}, \mathrm{e}_{\mathrm{x}}=\frac{T x}{n x}$

\section{Data analysis}

The mean duration of each stage of the FAW life cycle in different temperatures was compared using a one-way analysis of variance (ANOVA) followed by Tukey's post hoc test at a $5 \%$ significant level.

\section{Results And Discussion}

\section{Biology of FAW}

The present results indicated that the mean longevity for each stage of development at three different temperatures was significantly $(p<0.05, d f=2)$ vary except for the egg hatching period. Where $1^{\text {st }}$ to $3^{\text {rd }}$ instar larvae recorded the longest longevity at T25 and $4^{\text {th }}$ to $6^{\text {th }}$ instar larval longevity was longer at T35 (Table 1). However, the total larval longevity was higher at T25 (20.17 days) and T35 (17.89 days) compare to the T30 (14.92 days). Conversely, pupal duration at T35 (5.75 days) was the shortest compared to the other tested temperatures. The longevity of female moths at T35 was significantly lower (5.66 days) than T30 and T25 (Table 1 ).

Table 1. Longevity (days) of each stage of the FAW life cycle in different temperatures. 


\begin{tabular}{llll}
\hline & \multicolumn{3}{c}{ Longevity (Days) $($ Mean \pm SD) } \\
\hline Particulars & $35^{\circ} \mathrm{C}$ & $30^{\circ} \mathrm{C}$ & $25^{\circ} \mathrm{C}$ \\
\hline Egg & $2.78 \pm 0.46^{\mathrm{a}}$ & $2.17 \pm 0.38^{\mathrm{a}}$ & $2.14 \pm 0.35^{\mathrm{a}}$ \\
1st instar & $2.78 \pm 0.42^{\mathrm{b}}$ & $2.33 \pm 0.50^{\mathrm{c}}$ & $3.14 \pm 0.79^{\mathrm{a}}$ \\
\hline 2nd instar & $2.38 \pm 0.76^{\mathrm{b}}$ & $1.92 \pm 0.60^{\mathrm{c}}$ & $3.02 \pm 0.85^{\mathrm{a}}$ \\
\hline 3rd instar & $2.71 \pm 0.75^{\mathrm{a}}$ & $2.13 \pm 0.60^{\mathrm{b}}$ & $2.72 \pm 0.88^{\mathrm{a}}$ \\
\hline 4th instar & $3.20 \pm 1.48^{\mathrm{a}}$ & $2.01 \pm 0.72^{\mathrm{b}}$ & $2.54 \pm 0.95^{\mathrm{a}}$ \\
\hline 5th instar & $4.00 \pm 0.70^{\mathrm{a}}$ & $2.81 \pm 0.82^{\mathrm{b}}$ & $2.81 \pm 0.72^{\mathrm{b}}$ \\
\hline 6th instar & $5.20 \pm 0.83^{\mathrm{a}}$ & $3.72 \pm 1.07^{\mathrm{b}}$ & $3.66 \pm 0.63^{\mathrm{b}}$ \\
\hline Pre pupae & $1.20 \pm 0.44^{\mathrm{b}}$ & $1.64 \pm 0.75^{\mathrm{a}}$ & $1.84 \pm 1.02 \mathrm{a}$ \\
\hline Pupae & $5.75 \pm 0.50^{\mathrm{b}}$ & $8.61 \pm 0.75^{\mathrm{a}}$ & $9.21 \pm 1.02 \mathrm{a}$ \\
\hline Total pre adult period & $29.50 \pm 4.43^{\mathrm{ab}}$ & $27.56 \pm 1.89^{\mathrm{b}}$ & $30.93 \pm 2.38^{\mathrm{a}}$ \\
\hline Male & - & $9.29 \pm 0.46$ & $10.00 \pm 0.75$ \\
\hline Total female duration & $5.00 \pm 1.73^{\mathrm{b}}$ & $9.38 \pm 2.06^{\mathrm{a}}$ & $9.00 \pm 1.60^{\mathrm{a}}$ \\
\hline Pre oviposition & & & \\
\hline Oviposition & - & & \\
\hline Post oviposition & & & \\
\hline
\end{tabular}

Values indicates mean \pm standard deviation (SD) (days) and different letters show significant differences at $5 \%$ significant level

Table 2. Cohort life table of Fall Armyworm at $35^{\circ} \mathrm{C}$ 


\begin{tabular}{llllllll}
\hline Stage & $\mathrm{n} \square$ & $\mathrm{l} \square$ & $\mathrm{d} \square$ & $\mathrm{q} \square$ & $\mathrm{e} \square$ & $\mathrm{L} \square$ & $\mathrm{T} \square$ \\
\hline Egg & 100 & 1.00 & 42 & 0.42 & 1.84 & 79 & 184.5 \\
1st instar & 58 & 0.58 & 36 & 0.62 & 1.81 & 40 & 105.5 \\
\hline 2nd instar & 22 & 0.37 & 7 & 0.31 & 2.97 & 18.5 & 65.5 \\
\hline 3rd instar & 15 & 0.68 & 2 & 0.13 & 3.13 & 14 & 47 \\
\hline 4th instar & 13 & 0.86 & 3 & 0.23 & 2.53 & 11.5 & 33 \\
\hline 5th instar & 10 & 0.76 & 2 & 0.2 & 2.15 & 9 & 21.5 \\
\hline 6th instar & 8 & 0.8 & 2 & 0.25 & 1.56 & 7 & 12.5 \\
\hline Pupae & 6 & 0.75 & 1 & 0.16 & 0.91 & 5.5 & 5.5 \\
\hline Adult & 5 & 0.83 & 5 & 1.00 & 0 & 0 & 0 \\
\hline Accumulated Survival & $5 \%$ & & & & & & \\
\hline Accumulated mortality & & & $=95 \%$ & & & & \\
\hline
\end{tabular}

The table indicates the; $n x=$ number of survivors at start of the age of interval $x, l x=$ Survival of female at age $x$, $\mathrm{dx}=$ number of dying during the age interval $\mathrm{x}$ to $\mathrm{x}+1$, $\mathrm{qx}=$ rate of mortality during the age interval $\mathrm{x}$ to $\mathrm{x}+1$, Lx is the number of individuals alive on the average during the age interval $x$ to $x+1$, Cumulative number of alive in age interval $x$ to $x+1, e_{x}=$ mean expectation of life for organism alive at the start of age $x(n=100)$.

The cohort life table result of each temperature revealed that the lowest survivorship at T35 resulted from $95 \%$ accumulated mortality (dx) from 100 eggs followed by five adults with a sex ratio (3:1). Besides high mortality was observed in the egg (42) and $1^{\text {st }}$ instar larval (36) stages with qx values 0.42 and 0.62 respectively (Table 2). The results further reveal that egg hatchability and survivorship of subsequent larval stage were highly dependent on temperature whereas constant T35 exhibited increase mortality of eggs, early instars and males are more prone to heat stresses and vulnerability.

Table 3. Cohort life table of Fall Armyworm temperature at $30^{\circ} \mathrm{C}$ 


\begin{tabular}{llllllll}
\hline Stages & $\mathrm{n} \square$ & $\mathrm{l} \square$ & $\mathrm{d} \square$ & $\mathrm{q} \square$ & $\mathrm{e} \square$ & $\mathrm{L} \square$ & $\mathrm{T} \square$ \\
\hline Egg & 150 & 1.00 & 13 & 0.08 & 4.64 & 143.5 & 696.5 \\
1st instar & 137 & 0.91 & 32 & 0.23 & 4.03 & 121 & 553 \\
\hline 2nd instar & 105 & 0.76 & 15 & 0.14 & 4.11 & 97.5 & 432 \\
\hline 3rd instar & 90 & 0.85 & 24 & 0.26 & 3.71 & 78 & 334.5 \\
\hline 4th instar & 66 & 0.73 & 0 & 0 & 3.88 & 66 & 256.5 \\
\hline 5th instar & 66 & 1 & 1 & 0.01 & 2.88 & 65.5 & 190.5 \\
\hline 6th instar & 65 & 0.98 & 2 & 0.03 & 1.92 & 64 & 125 \\
\hline Pupae & 63 & 0.96 & 4 & 0.06 & 0.96 & 61 & 61 \\
\hline Adult & 59 & 0.93 & 59 & 1.00 & 0 & 0 & 0 \\
\hline Accumulated survival & $39 \%$ & & & & & & \\
\hline Accumulated mortality & & & $61 \%$ & & & & \\
\hline
\end{tabular}

The table indicates the; $\mathrm{nx}=$ number of survivors at start of the age of interval $\mathrm{x}, \mathrm{lx}=$ Survival of female at age $\mathrm{x}$, $\mathrm{dx}=$ number of dying during the age interval $\mathrm{x}$ to $\mathrm{x}+1, \mathrm{qx}=$ rate of mortality during the age interval $\mathrm{x}$ to $\mathrm{x}+1, \mathrm{Lx}$ is the number of individuals alive on the average during the age interval $x$ to $x+1$, Cumulative number of alive in age interval $x$ to $x+1, e_{x}=$ mean expectation of life for organism alive at the start of age $x(n=150)$.

On the other hand, the highest survivorship was observed at T30 (39\%) (Table 3) with less accumulated mortality rate (61\%) were resulting in 59 adults from 150 eggs. In addition, egg mortality was less compared to the T35 and the highest $d x$ was in the $1^{\text {st }}$ instar larval stage (32). Similarly, the qx values are very low in egg $(0.08), 5^{\text {th }}(0.01), 6^{\text {th }}(0.03)$ and pupal $(0.06)$ stages. Though, this temperature range lies between optimum thermal condition recorded the considerably higher mortality percentage due to constant temperature conditions and daily handling the larvae for observation influencing the natural behavior of the FAW.

Table 4. Cohort life table of Fall Armyworm temperature at $25^{\circ} \mathrm{C}$ 


\begin{tabular}{llllllll}
\hline Stages & $\mathrm{n} \square$ & $\mathrm{l} \square$ & $\mathrm{d} \square$ & $\mathrm{q} \square$ & $\mathrm{e} \square$ & $\mathrm{L} \square$ & $\mathrm{T} \square$ \\
\hline Egg & 150 & 1.00 & 22 & 0.14 & 4.18 & 139 & 628 \\
1st instar & 128 & 0.85 & 39 & 0.3 & 3.82 & 108.5 & 489 \\
\hline 2nd instar & 89 & 0.69 & 22 & 0.24 & 4.27 & 78 & 380.5 \\
\hline 3rd instar & 67 & 0.75 & 5 & 0.07 & 4.51 & 64.5 & 302.5 \\
\hline 4th instar & 62 & 0.92 & 0 & 0 & 3.83 & 62 & 238 \\
\hline 5th instar & 62 & 0 & 3 & 0.04 & 2.83 & 60.5 & 176 \\
\hline 6th instar & 59 & 0.95 & 0 & 0 & 1.95 & 59 & 115.5 \\
\hline Pupae & 59 & 0 & 5 & 0.08 & 0.95 & 56.5 & 56.5 \\
\hline Adult & 54 & 0.91 & 54 & 1.00 & 0 & 0 & 0 \\
\hline Accumulated survival & $36 \%$ & & & & & & \\
\hline Accumulated mortality & & & & & & &
\end{tabular}

The table indicates the; $\mathrm{nx}=$ number of survivors at start of the age of interval $\mathrm{x}, \mathrm{l} \mathbf{x}=$ Survival of female at age $\mathrm{x}$, $\mathrm{dx}=$ number of dying during the age interval $\mathrm{x}$ to $\mathrm{x}+1, \mathrm{qx}=$ rate of mortality during the age interval $\mathrm{x}$ to $\mathrm{x}+1, \mathrm{Lx}$ is the number of individuals alive on the average during the age interval $x$ to $x+1$, Cumulative number of alive in age interval $x$ to $x+1, e_{x}=$ mean expectation of life for organism alive at the start of age $x(n=150)$.

Similar to T30, higher survivorship (36\%) was observed with less mortality at T25 than T35. It resulted 54 adults with the sex ratio of 2:1. However, as similar to the other two temperature conditions high qx was found in the $1^{\text {st }}$ instar stage (0.3) meantime the zero qx values were found in the $4^{\text {th }}$ and $6^{\text {th }}$ instar larval stages.

Table 5: Life fecundity table of fall armyworm under different temperatures 


\begin{tabular}{|c|c|c|c|}
\hline \multirow[t]{2}{*}{ Population growth statistics } & \multicolumn{3}{|c|}{ Temperature } \\
\hline & $30^{\circ} \mathrm{C}$ & $25^{\circ} \mathrm{C}$ & $35^{\circ} \mathrm{C}$ \\
\hline Net reproductive rate $\left(R_{0}\right)$ & 132.17 & 118.74 & 0.00 \\
\hline Mean length of generation (Tc) & 32.3138 & 35.90 & 0.00 \\
\hline Innate capacity for an increase in numbers (rm) (Females/ Female/day & 0.1511 & 0.1330 & 0.00 \\
\hline Arbitrary 'rm' (rc) & $0.15-0.16$ & $0.15-0.16$ & 0.00 \\
\hline Corrected 'rm' (Female/ Females/day) & 0.1577 & 0.1330 & 0.00 \\
\hline Corrected generation time $(\mathrm{T})$ (days) & 30.97 & 35.91 & 0.00 \\
\hline Finite rate of increase in numbers $(\lambda)$ (Female/Females/ day) & 1.1702 & 1.1417 & 0.00 \\
\hline Weekly multiplication of population $\left(\lambda^{7}\right)$ & 3.004 & 2.5285 & 0.00 \\
\hline Hypothetical $F_{2}$ females & 17468.20 & 14099.18 & 0.00 \\
\hline
\end{tabular}

The present study revealed that, female pre-oviposition period remained at 28 to 30 days and pivotal age was 31 to 33 days at T30. The first batch of eggs was laid by females after 31 days with $\mathrm{mx}$ of 160.27 and lasted until the 38 days $(m x=11)$, where $\mathrm{lx}$ values of 0.28 and 0.03 respectively for 31 and 38 days (Figure 1). At 32 days of pivotal age, the first female mortality was recorded on the 4 days after the emergence and the female mortality increased, as evidenced by a steady decrease in the Ix values. It had a $\mathrm{Ix}$ value of 0.24 on the 32 days of pivotal age. The maximum mean progeny production/day $(\mathrm{mx}=$ 168.57) was reported on the 32 days.

As same in T25 pre oviposition and oviposition periods took comparatively longer durations while the first batch of eggs was laid by females on the 34 days. They had $m x$ of 258.86 and lasted until the 42 day $(\mathrm{mx}=09)$, with $\mathrm{Ix}$ values of 0.17 and 0.03 respectively (Table 5$)$. After the 34 days of pivotal age, the first female mortality was observed on the 3 days after the emergence. Moreover, the net reproductive rate (Ro) was 132.17 and 118.74 respectively in $T 30$ and $T 25$, which represents the ratio of total female birth in a generation. Similarly, the average period of generation time (Tc) was lower in T30 (32.31 days) compared to T25 (35.90 days). However daily finite rate of increase in number $(\lambda)$ in T30 1.1702 females/female/day with a population doubling time of 3.004 days whereas in T25 $(\lambda) 1.1417$ females/female/day and a population doubling time of 2.5285 days. The intrinsic rate of natural increase in number (rm) was 0.1511 females/ female/ day (T30) and 0.1330 females/ female/ day (T25). Finally, the hypothetical female population in the $F_{2}$ generation was found to be higher in T30 (17468.20) than T25 $(14,099.18)$ was reported (Table 5). Similar observations were reported earlier by 
Ashok et al., (2020) by evaluating adult longevity, oviposition period, fecundity and fertility using 30 pairs of FAW at $27^{\circ} \mathrm{C}$. They reported adult longevity of 12.6 days and 11.1 days for females and males, respectively.

Based on our findings, the net reproductive rate (Ro) was $480.33(n=36)$ with a generation time (Tc) of 31.24 days. The determined intrinsic rate of natural increase $(\mathrm{rm})$ and the finite rate of increase $(\lambda)$ was 0.20 and 1.22 females/ female/ day, respectively. The population doubling time was found to be 3.51 days. The FAW life cycle follows complete metamorphosis (holometabolous) consisting of 4 stages viz, egg, larva, pupae and adult stages (Assefa \& Ayalew., 2019). The longevity of each stage was varying different day intervals viz, 2 days for egg hatching, larval longevity (12 days), pupal ( 7 days) and adult longevity (14 days) (Tendeng et al., 2019). However, several authors reported various longevity for different stages of FAW according to the various climatic conditions (Ashok et al., 2020; Plessis et al., 2020). As per the biological parameters of FAW at $25^{\circ} \mathrm{C}$ Kalyan et al., (2020) reported that the larval, pupal, pre oviposition, oviposition and post-oviposition period were 16.97, 8.96, 3.30, 16.97, 8.96, 3.47, 2.96 and 6.13 days respectively but those durations were in disagreement with present findings. However, present findings were in agreement with results reported by Pitre \& Hogg (1983) when the larvae were reared at $25^{\circ} \mathrm{C}$. The total life cycle was completed within 30 days at the daily temperature at $28^{\circ} \mathrm{C}$ during worm climate conditions but may extend up to 60-90 days in cooler temperatures including 20-30 days of pupal period. Overall, the present results indicated that total life cycle durations were $34.5 \pm$ $1.08,36.07 \pm 0.69$ and $38.62 \pm 0.70$ days for T35, T30 and T25 respectively and were in line with the previous studies.

The FAW female moth normally deposits the majority of her eggs during the first 4 to 5 days of life followed by 3-4 days pre oviposition period, but oviposition can continue up to 3 weeks. Adult life expectancy is estimated to be about 10 days on average, with a range of 7-21 days (Prasanna et al., 2018). According to our study pre-oviposition periods lay between 2.5 to 3 days and total female longevity extends to a maximum of 9 days for both T25 and T30 conditions while 5 days of total life durations are reported at T35.

In higher temperature conditions like T35 results, only 5 adults survive from 100 eggs while the remainder fails to rescue compared to the other two temperature conditions. This may be due to continuous exposure of high temperature to eggs at early development instars tend to increase water losses through the unsclerotized cuticle while on the other hand increasing metabolic rates may lead to rapid depleting the foods reserves. In contrast, other tested two temperatures may lie within the optimum thermal range required for their growth and development. Our observation further confirms that males were more susceptible to rising temperatures than females. Due to the low male to female ratio at T35, the progeny fitness became lower and mating was not taken place thereby both males and females were died within 6-7 days without laying eggs. Therefore, it was not possible to construct the life fecundity table, mean length of a generation, innate capacity for an increase in numbers and finite rate of increase in numbers of FAW at T35. Further, our results indicated that the egg hatchability and survivorship of the first instar larvae were more susceptible to temperature changes. Therefore, the changing temperature can be used 
in the field conditions at the stage of eggs and first instar larvae for the manipulation of FAW populations. Our findings could be useful implicating in pest forecasting and integrated pest management programs in the field and control environmental conditions.

\section{Declarations}

\section{Author Contribution}

ADNTK and GKMMKR conceived and designed the study. AMKGM and MBA conducted experimental work, data collected. ADNTK and GKMMKR analyzed the data, and drafted the manuscript. ANM and ADNT supervised the AMKGM and MBA corrected the draft manuscript and improved. SRS supply the planting materials and improved the manuscript. All authors critically revised the draft and approved the final manuscript for publication.

\section{Acknowledgement}

This work has been completed as part of the Accelerating Higher Education Expansion and Development (AHEAD) RIC project on Sustainable Management of Fall Armyworm on Maize and is financially supported by the AHEAD RIC World Bank funds (Grant number: 6026-LK/8743-LK) .

\section{Disclosure}

The authors declare that they have no any conflicts of interest.

\section{References}

Aguilon DJD, Velasco LRI (2015) Effects of larval rearing temperature and host plant condition on the development, survival, and coloration of African armyworm, Spodoptera exempta Walker (Lepidoptera: Noctuidae). Journal of Environmental Science and Management 18(1): 54-60.

Andrewartha HC, Birch CC (1954) The distribution and abundance of animals. University of Chicago Press, Chicago. p. 20

Ashok K, Kennedy JS, Geethalakshmi V, Jeyakumar P, Sathiah N Balasubramani V (2020) Lifetable study of fall armyworm Spodoptera frugiperda (J. E. Smith) on maize. Indian Journal of Entomology 82(3), 574-579. https://doi.org/10.5958/0974-8172.2020.00143.1

Assefa F, Ayalew D (2019) Status and control measures of fall armyworm (Spodoptera frugiperda) infestations in maize fields in Ethiopia: A review Cogent Food \& Agriculture 5(1), 1641902. https://doi.org/10.1080/23311932.2019.1641902

Atwal AS, Bains SS (1974). Applied Animal Ecology, Kalyani Publishers, Ludhiana, pp. 177-179 
Prasanna BM, Joseph EH, Eddy R VM (2018) Fall Armyworm in Africa. In A Guide for Integrated Pest Management (1st ed., p. 120).

Begon M, Townsend CR, Harper JL (2006) Ecology: From individuals to Ecosystems, fourth edition Blackwell Publishing Ltd Oxford, United Kingdom

Cruz I, Figueiredo MLC, Oliveira AC, Vasconcelos CA (1999) Damage of Spodoptera frugiperda (Smith) in different maize genotypes cultivated in soil under three levels of aluminium saturation. International Journal of Pest Management 45(4), 293-296. https://doi.org/10.1080/096708799227707

De Groote H, Kimenju SC, Munyua B, Palmas S, Kassie M, Bruce A (2020) Spread and impact of fall armyworm (Spodoptera frugiperda J.E. Smith) in maize production areas of Kenya. Agriculture Ecosystems and Environment 292, 106804. https://doi.org/10.1016/j.agee.2019.106804

Du Plessis H, Schlemmer ML, Van den Berg J (2020) The effect of temperature on the development of Spodoptera frugiperda (Lepidoptera: Noctuidae). Insects 11(4). https://doi.org/10.3390/insects 11040228

Early R, Bradley BA, Dukes JS, Lawler JJ, Olden JD, Blumenthal DM, Gonzalez P, Grosholz ED, Ibañez I, Miller LP Sorte CJ, (2016) Global threats from invasive alien species in the twenty-first century and national response capacities. Nature communications,7(1), pp.1-9.

Goergen G, Kumar PL, Sankung SB, Togola A, Tamo, M (2016) First report of outbreaks of the fall armyworm Spodoptera frugiperda (J E Smith) (Lepidoptera: Noctuidae), a new alien invasive pest in the West and Central Africa. PLOS ONE 11(10): 1-15.

Hagstrum DW, Hagstrum, WR (1970) A simple device for producing fluctuating temperatures, with an evaluation of the ecological significance of fluctuating temperatures. Annual Entomological Society of America 63: 1385-1389

Howe RW (1953) The rapid determination of intrinsic rate increase of an insect population, Annual review of applied Biology 40: 134- 151

Howe RW (1967) Temperature effects on embryonic development in insects. Annual Review of Entomology 12: 15-42.

Jaworski T, Hilszczański J (2014) The effect of temperature and humidity changes on insects development their impact on forest ecosystems in the expected climate change. Forest Research Papers 74(4), 345-355. https://doi.org/10.2478/frp-2013-0033

Kalyan D, Mahla MK, Babu SR, Kalyan RK, Swathi P (2020) Biological Parameters of Spodoptera frugiperda (J.E. Smith) under Laboratory Conditions. International Journal of Current Microbiology and Applied Sciences, 9(5), 2972-2979 
Krebs CJ (1978) Ecology: The experimental analysis of distribution and abundance (2nd edn.) Harper and Row Publishers

Krebs CJ (2001) Ecology: The experimental analysis of distribution and abundance (5th edn.) Benjamin Cummings, an important of Addison Wesley Longman Inc. 695

Kyi A, Zalucki MP, Titmarsh IJ (1991) An experimental study of early-stage survival of Helicoverpa armigera (Lepidoptera: Noctuidae) on cotton. Bulletin of Entomological. Research 81: 263-271.

Paini DR, Sheppard AW, Cook DC, De Barro PJ, Worner SP, Thomas MB (2016) Global threat to agriculture from invasive species. Proceedings of the National Academy of Sciences 113(27), pp.7575-7579

Patil, RA, Mehta DM, Jat BL (2014) Studies on life fecundity tables of Spodoptera litura Fabricius on tobacco Nicotiana tabacum Linnaeus. Entomol Ornithol Herpetol3(118), pp.2161-0983.

Perera N, Magamage M, Kumara A, Galahitigama H, Dissanayake K, Wekumbura C, Iddamalgoda P, Siriwardhana C, Yapa P (2019). Fall armyworm (FAW) epidemic in Sri Lanka: Ratnapura district perspective. International Journal of Entomological Research 07(01): pp. 9-18.

https://doi.org/10.33687/entomol.007.01.2887

Pitre HN, Hogg DB (1983) Development of the fall armyworm on cotton, soybean and corn. Journal of the Georgia Entomological Society 18: 187-194.

Pratt CF, Constantine KL, Murphy ST (2017) Economic impacts of invasive alien species on African smallholder livelihoods. Global Food Security 14:31-37. https://doi.org/10.1016/j.gfs.2017.01.011

Sarmento RA, Agular RWS, Vieira SMJ, de Oliveira HG, Holtz AM (2002) Biology review, occurrence and control of Spodoptera frugiperda (Lepidoptera, Noctuidae) in corn in Brazil. Bioscience Journal (Brazil) $18,41-48$

Sharanabasappa, Kalleshwaraswamy, CM, Maruthi MS, Pavithra HB (2018) Biology of invasive fall armyworm Spodoptera frugiperda (J.E. Smith) (Lepidoptera: Noctuidae) on maize. Indian Journal of Entomology 80(3), 540. https://doi.org/10.5958/0974-8172.2018.00238.9

Sisay B, Tefera T, Wakgari M, Ayalew G, Mendesil E (2019) The efficacy of selected synthetic insecticides and botanicals against fall armyworm, Spodoptera frugiperda, in maize. Insects 10(2).

https://doi.org/10.3390/insects 10020045

Tendeng E, Labou B, Diatte M, Djiba S, Diarra K (2019) The fall armyworm Spodoptera frugiperda (J.E. Smith), a new pest of maize in Africa: biology and first native natural enemies detected. International Journal of Biological and Chemical Sciences 13(2), 1011. https://doi.org/10.4314/ijbcs.v13i2.35

Tobin, P.C., Nagarkatti, S. and Saunders, M.C. (2003). Phenology of Grape Berry Moth (Lepidoptera: Tortricidae) in the cultivated grape at selected geographic locations. Environmental Entomology 32(2): 
Westbrook JK, Nagoshi RN, Meagher RL, Fleischer SJ, Jairam S (2016) Modelling seasonal migration of fall armyworm moths. International Journal of Biometeorology 60(2), 255-267.

https://doi.org/10.1007/s00484-015-1022-x

Wijerathna DMIJ, Ranaweera,P H, Perera RNN, Dissanayake MLMC, Kumara JBDAP (2021) Biology and feeding preferences of Spodoptera frugiperda (Lepidoptera: Noctuidae) on maize and selected vegetable crops. Journal of Agricultural Sciences - Sri Lanka 16(1), 126-134.

https://doi.org/10.4038/jas.v16i1.9190

Figures

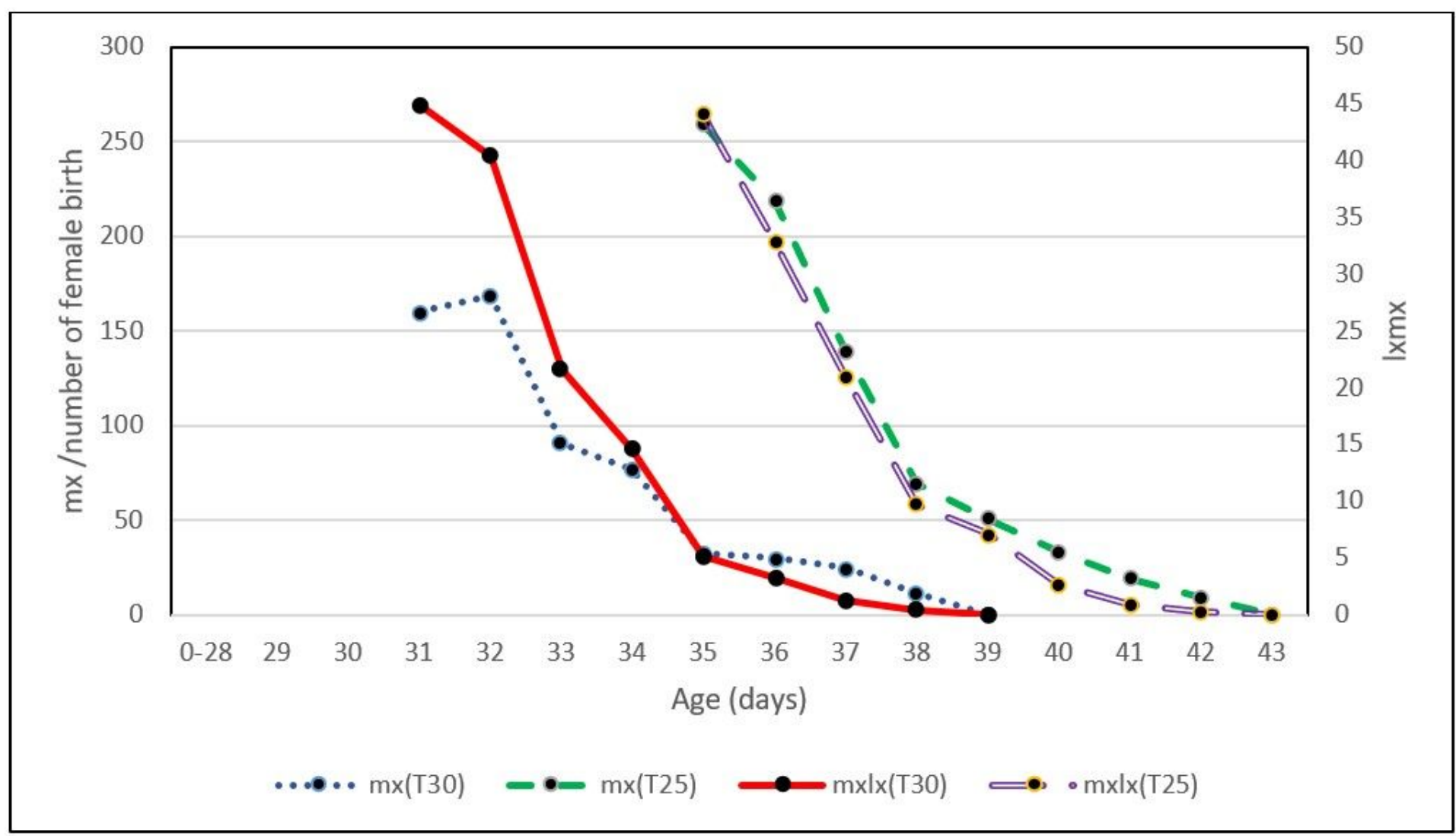

Figure 1

Age-specific fecundity (mx), age-specific mortality (Ixmx) of fall armyworm at $25^{\circ} \mathrm{C}$ and $30^{\circ} \mathrm{C}$ temperatures under control conditions $(n>100)$. 